\title{
Crocin Improves Oxidative Stress by Potentiating Intrinsic Anti-Oxidant Defense Systems in Pancreatic Cells During Uncontrolled Hyperglycemia
}

\author{
Habib Yaribeygi ${ }^{1,2}$, Ali Noroozadeh ${ }^{3}$, Mohammad Taghi Mohammadi ${ }^{3 *}$, Thomas P. \\ Johnston ${ }^{4}$, Amirhossein Sahebkar ${ }^{5,6 *}$ \\ ${ }^{1}$ Health Research Center, Baqiyatallah University of Medical Sciences, Tehran, Iran \\ ${ }^{2}$ Chronic Kidney Diseases Research Center, Baqiyatallah University of Medical Sciences, Tehran, Iran \\ ${ }^{3}$ Department of Physiology and Biophysics, School of Medicine, Baqiyatallah University of Medical Sciences, Tehran, Iran \\ ${ }^{4}$ Division of Pharmaceutical Sciences, School of Pharmacy, University of Missouri-Kansas City, Kansas City, Missouri, United States \\ ${ }^{5}$ Biotechnology Research Center, Pharmaceutical Technology Institute, Mashhad University of Medical Sciences, Mashhad, Iran \\ ${ }^{6}$ School of Pharmacy, Mashhad University of Medical Sciences, Mashhad, Iran
}

\section{Key Words}

oxidative stress, pancreas, crocin, MDA

\begin{abstract}
Introduction: Oxidative stress (OS) during uncontrolled hyperglycemia has a pivotal role in pancreatic dysfunction. Our study aimed to demonstrate that crocin can potentiate anti-oxidant defense systems of pancreatic cells to improve oxidative stress.

Methods: Male Wistar rats were divided randomly into four groups: a normal group, a normal-treated group, a diabetic group and a diabetic-treated group $(n=6$ rats per group). Diabetes was induced by a single dose of streptozotocin $(45 \mathrm{mg} / \mathrm{kg} / \mathrm{IV})$. The treated groups received crocin daily for 8 weeks ( $40 \mathrm{mg} / \mathrm{kg} / \mathrm{IP}$ ). At the end of the experiment, rats were sacrificed and pancreas tissue was obtained. Subsequently, the concentrations of malondialdehyde (MDA), nitrate and glutathione as well as the enzymatic activities of catalase and superoxide dismutase (SOD) were determined in all animals. Data were analyzed by two-way ANOVA with appropri-
\end{abstract}

Received: Nov 14, $2017 \quad$ Reviewed: Nov 01, $2018 \quad$ Accepted: May 09, 2019

(1) This is an Open-Access article distributed under the terms of the Creative Common Attribution Non-Commercial License (http://creativecommons.org/licenses/by-nc/4.0/) which permits unrestricted noncommercial use, distribution, and reproduction in any medium, provided the original work is properly cited.

@ This paper meets the requirements of KS X ISO 9706, ISO 9706-1994 and ANSI/NISO Z39.48-1992 (Permanence of Paper) ate post hoc testing and a probability value of $\mathrm{P}<0.05$ was considered to represent a statistically significant difference in mean values.

Results: Uncontrolled hyperglycemia weakened the anti-oxidant system by decreasing SOD and catalase enzyme activity in pancreatic tissues and induced OS by increasing the MDA content in diabetic non-treated animals. Crocin potentiated the anti-oxidant defense system by increasing the activity of both SOD and catalase, and improved OS by diminishing MDA production in pancreatic cells of rats contained in the diabetic-treated group.

Conclusion: Based on our results, it is concluded that uncontrolled hyperglycemia can weaken the anti-oxidant defense system and cause the development of OS. Also, crocin can improve OS in pancreatic cells by potentiating the anti-oxidant defense system.

\section{Introduction}

In the diabetic state, normal metabolism of substrates deviates to unusual pathways. This phenomenon can result in the production of hazardous by-products e.g. reactive oxygen species. Reactive oxygen species pro- 
duction in uncontrolled hyperglycemia can occur through several pathways such as activation of protein kinase C, glucose autoxidation, methylglyoxal formation, sorbitol formation and oxidative phosphorylation [1]. If these free radicals are able to overcome the intrinsic antioxidant defense system, then they create a condition known as oxidative stress (OS) [1-3]. OS is a common phenomenon in uncontrolled hyperglycemia, which allows free radicals to exert their dangerous effects on many cellular elements (e.g. DNA, proteins and cellular structures) $[2,4]$. These processes may finally lead to apoptosis and a disturbance in tissue function [3]. Consequently, readjusting the balance between oxidants and endogenous compounds and enzymes that function as antioxidants is a significant issue in diabetes [5].

One of the most susceptible tissues against OS damage is the pancreas [6]. Pancreatic cells have a weak intrinsic anti-oxidative system when compared to other tissues. Therefore, they are more susceptible to oxidative damage than cells in other tissues [3]. Also, previous studies have shown that OS has a pivotal role in reducing pancreatic cell function during uncontrolled diabetes $[3,6,7]$. OS can affect gene expression or induce apoptosis of pancreatic cells $[8,9]$. Kakkar et al. showed that during diabetes, the enzymatic activity of superoxide dismutase, glutathione peroxidase and catalase were diminished and thus, OS subsequently developed, which led to impaired pancreatic cell function [7]. It has been demonstrated that hyperglycemia decreases beta cell function so as to reduce the release of insulin [3]. Diabetes decreases insulin gene expression and insulin release by several mechanisms e.g. loss of pancreatic and duodenal homeobox 1 (PDX-1) and RIPE-3bl activator proteins [3]. Glucotoxicity in pancreatic islet cells was determined to directly cause a reduction in the expression of PDX-1 [10]. These proteins are the two primary activators of insulin gene promoters and, in a state in which these two proteins are deficient, insulin expression declines [3]. Other studies have also demonstrated that hyperglycemia up-regulated CCAAT and CCAAT-enhancer-binding protein $\beta$ (C/EBP $\beta$ ), which are two repressors for insulin gene promoters [11, 12]. Briaud et al. suggested that lipotoxicity occurred during diabetes as a result of OS and that OS directly exaggerated glucotoxicity [13]. Furthermore, these same authors showed that OS resulted in a deterioration of pancreatic islet cell function [13].

Saffron (Crocus sativus L.) I a medicinal plant that is reputed with traditional and modern therapeutic uses against a wide range of human diseases [14-19]. Crocin is a plant-derived and valuable water-soluble constituent of saffron and possesses several pharmacological actions including antioxidant effects [20-25]. It can react with free radicals more rapidly and with greater affinity than many other antioxidant agents, leading to the neutralization of the harmful effects of free radicals [26]. Previous studies have shown that crocin has antioxidant activity in different tissues e.g. in neurons [20], liver and brain [27, 28], cartilage and joints [29], kidneys and spleen [30, 31]. However, there is no evidence concerning its function in pancreatic cells, especially in uncontrolled hyperglycemia. Ochiai documented that crocin has a greater anti-oxidative ca- pacity than $\alpha$-tocopherol and can prevent neuronal cell death in a state of OS [20]. El Beshbishy et al. demonstrated that crocin diminishes OS in liver tissue by enhancing the expression of anti-oxidant enzymes and scavenging free radicals [27]. Similarly, Janeshwari et al. showed that crocin modulated OS in hepatic cells by stimulating the expression of anti-oxidant enzymes and augmenting the anti-oxidant defense system [30].

In this study, we evaluated the effects of uncontrolled hyperglycemia in the development of OS in pancreatic tissue. Next, we evaluated the effects of crocin with regard to re-adjusting oxidative balance in pancreatic cells.

\section{Materials and Methods}

\subsection{Animals}

Male Wistar rats (200-230 g) were kept in standard polyester cages ( 2 rats in each cage) in a room maintained at a standard temperature $\left(22 \pm 2^{\circ} \mathrm{C}\right)$ and humidity $(55 \pm 5 \%)$ with a 12-h light/dark cycle and free access to water and standard rodent chow. All animal protocols in the study were approved by the institutional animal ethics committee of the Baqiyatallah University of Medical Sciences, which follows the NIH Guidelines for the care and use of laboratory animals. Rats were randomly divided into four groups ( $\mathrm{n}=6$ rats per group): normal, normal-treated, diabetic and diabetic-treated.

\subsection{Induction of diabetes}

Diabetes was induced by a single intravenous injection of streptozotocin $(45 \mathrm{mg} / \mathrm{kg})$ which was purchased from Sigma Aldrich and dissolved in cold saline. After 72 hours, blood samples were obtained from the rats' tail vein to monitor blood glucose using a glucometer (Bionime, Switzerland). Rats with a plasma glucose concentration above $400 \mathrm{mg} / \mathrm{dl}$ were considered as diabetic and were subsequently divided into two diabetic groups (treated and non-treated) in a random fashion.

\subsection{Treatments}

Crocin was obtained from Sigma Aldrich and dissolved in fresh distilled water daily. Two treatment groups (normal-treated and diabetic-treated) received crocin daily for 8 weeks ( $40 \mathrm{mg} / \mathrm{kg} / \mathrm{IP})$.

\subsection{Sampling}

After 8 weeks, blood samples were collected for blood glucose testing and the animals were sacrificed to harvest pancreatic tissue to determine the concentrations of nitrate (NOx), malondialdehyde (MDA) and glutathione (GLT), as well as the enzymatic activities of catalase and superoxide dismutase (SOD). Serum was obtained following centrifugation at $3000 \mathrm{rpm}$ for $15 \mathrm{~min}$ and the concentration of glucose was determined using commercially available kits (Pars-Azmoon, Iran). 
Pancreatic tissue samples were weighed and then homogenization medium [phosphate buffer $(0.1 \mathrm{~mol}, \mathrm{pH}$ 7.4)] was added. After homogenizing the tissues on ice with an electric homogenizer, samples were centrifuged (20 minutes at $4^{\circ} \mathrm{C}$ and $4000 \mathrm{rpm}$ ) and the supernatant was removed as a pancreatic cytosolic extract and stored at $-80^{\circ} \mathrm{C}$ until the time for biochemical assessments.

\subsection{NOx assay}

The NOx in the 'cytosolic extract' was measured by the well-known Griess method, which is a colorimetric assay. Cytosolic extract $(0.1 \mathrm{ml})$ was deproteinated by adding 0.2 $\mathrm{ml}$ of zinc sulfate solution and the mixture was centrifuged for 20 minutes at $4000 \mathrm{rpm}$ and $4^{\circ} \mathrm{C}$ to separate the supernatant for quantification of NOx. Sulfanilamide $(0.05 \mathrm{ml}$ of a $0.01 \%$ solution) and $0.05 \mathrm{ml}$ of a $0.01 \% \mathrm{~N}$-[1-naphthyl] ethylenediamine di-hydrochloride (NED) solution were incubated for 30 minutes in the dark at $37^{\circ} \mathrm{C}$. Next, the absorbance of the solution was determined at a wavelength of $540 \mathrm{~nm}$. The concentration of nitrite was estimated from a standard curve generated from the absorbance of each sodium nitrate solution. Finally, the nitrite-nitrate levels were expressed as $\mu \mathrm{g} / \mathrm{mg}$ protein.

\subsection{SOD activity}

The activity of SOD was determined by the Winterbourn method [32], which was developed based on the ability of SOD to inhibit the reduction of nitro-blue tetrazolium by superoxide. Potassium phosphate buffer (0.067 M; pH 7.8) was added to $0.1 \mathrm{M}$ EDTA containing $0.3 \mathrm{mM}$ sodium cyanide, $1.5 \mathrm{mM}$ nitro-blue tetrazolium, and $0.1 \mathrm{ml}$ of the sample. Next, $0.12 \mathrm{mM}$ riboflavin was added to each sample to initiate the reaction and the sample was then incubated for $10 \mathrm{~min}$. The optical absorbance of the sample was recorded at $560 \mathrm{~nm}$ after 5 minutes on a spectrophotometer. The amount of enzyme required to produce $50 \%$ inhibition was taken as $1 \mathrm{U}$ and the results were expressed as $\mathrm{U} / \mathrm{mL}$.

\subsection{Catalase activity}

The activity of catalase in tissue was evaluated using the Aebi method [33]. The reaction mixture contained $0.85 \mathrm{ml}$ of potassium phosphate buffer (50 mM; pH 7.0) and 0.1 $\mathrm{ml}$ of the tissue homogenate. The sample was incubated at room temperature for $10 \mathrm{~min}$. The reaction was initiated by the addition of $0.05 \mathrm{ml}$ of $\mathrm{H} 2 \mathrm{O} 2$ [ $30 \mathrm{mM}$ prepared in potassium phosphate buffer (50 mM; pH 7.0)] and the decrease in the optical absorbance over $3 \mathrm{~min}$ at $240 \mathrm{~nm}$ was recorded. The enzyme activity was expressed as $1 \mu$ mole $\mathrm{H} 2 \mathrm{O} 2$ decomposed over the $3 \mathrm{~min}$ interval and expressed as $\mathrm{U} / \mathrm{mL}$.

\subsection{Determination of GLT}

GLT content was evaluated using the Tietz method [34].
Cellular protein content was precipitated using a 5\% sulfosalicylic acid addition and then removed by centrifugation (2000 $\mathrm{g}$ for $10 \mathrm{~min}$ ). The GLT in the supernatant was assayed in the following reaction mixture; $100 \mu \mathrm{l}$ of protein-free supernatant of the cell lysate, $800 \mu \mathrm{l}$ of 0.3 $\mathrm{mM} \mathrm{Na} 2 \mathrm{HPO} 4$, and $100 \mu \mathrm{l}$ of $0.04 \%$ 5-5'-dithiobis [2- nitrobenzoic acid] in $0.1 \%$ sodium citrate. The absorbance of 5-5'-dithiobis [2-nitrobenzoic acid] was recorded at 412 $\mathrm{nm}$ for $5 \mathrm{~min}$. A standard curve for GLT was constructed and the sensitivity of the measurement for GLT was determined to be between 1 and $100 \mu \mathrm{M}$. The concentration of GLT was expressed as $\mathrm{nmol} / \mathrm{mL}$.

\subsection{Lipid peroxidation assay}

The end product of the lipid peroxidation process was assayed by measuring MDA content by the method developed by Satoh [35]. Tissue homogenate $(0.5 \mathrm{ml})$ was added to $1.5 \mathrm{ml}$ of $10 \%$ trichloroacetic acid. Next, the sample was vortexed and incubated at room temperature for $10 \mathrm{~min}$. Subsequently, $1.5 \mathrm{ml}$ of supernatant and $2 \mathrm{ml}$ of thiobarbituric acid $(0.67 \%)$ were added and placed in a boiling water bath in sealed tubes for $30 \mathrm{~min}$. The samples were then allowed to cool at room temperature for $20 \mathrm{~min}$. Thereafter, $1.25 \mathrm{ml} \mathrm{N}$-butanol was added, the mixture vortexed, and then centrifuged for $5 \mathrm{~min}$ at $2000 \mathrm{~g}$. The resulting supernatant was removed and the optical absorbance measured at $532 \mathrm{~nm}$ on a spectrophotometer. The MDA content was determined by using 1,1,3,3-tetraethoxypropane as the standard. The concentration of MDA was expressed as $\mathrm{nmol} / \mathrm{ml}$.

\subsection{Statistical Analyses}

The results were expressed as the mean \pm SEM. All statistical assessments were performed using a two-way analysis of variance (ANOVA) and the Tukey post hoc test. In all statistical comparisons, a $\mathrm{P}<0.05$ was considered a statistically-significant difference between mean values.

\section{Results}

\subsection{Blood glucose changes}

Table 1 shows representative changes of mean blood glucose in all groups at the end of 8 weeks.

\subsection{Effects of diabetes and crocin on ni- trate content}

Figure 1 shows representative changes of nitrate content in $\mathrm{nmol} / \mathrm{mL}$ in all experimental groups. The mean value of the nitrate content in the normal group was $18.59 \pm 2.03$ $\mathrm{nmol} / \mathrm{mL}$. Crocin did not change the nitrate level in normal-treated rats. Uncontrolled hyperglycemia decreased the nitrate level significantly to $13.7 \pm 2.74 \mathrm{nmol} / \mathrm{mL}(\mathrm{P}<$ $0.001)$. Treatment with crocin in diabetic animals did not significantly change the levels of nitrate in pancreatic cells. 
Table 1 Mean blood glucose values in experimented groups

\begin{tabular}{cc}
\hline Groups & $\begin{array}{c}\text { Mean Blood Glucose (day 56) } \pm \text { SD } \\
(\mathbf{m g} / \mathbf{d l})\end{array}$ \\
\hline Normal & $96.35 \pm 18.09$ \\
\hline Normal-Treated & $81.57 \pm 20.58$ \\
\hline Diabetic & $422.68 \pm 23.59$ \\
\hline Diabetic-Treated & $380.71 \pm 27.74$ \\
\hline
\end{tabular}

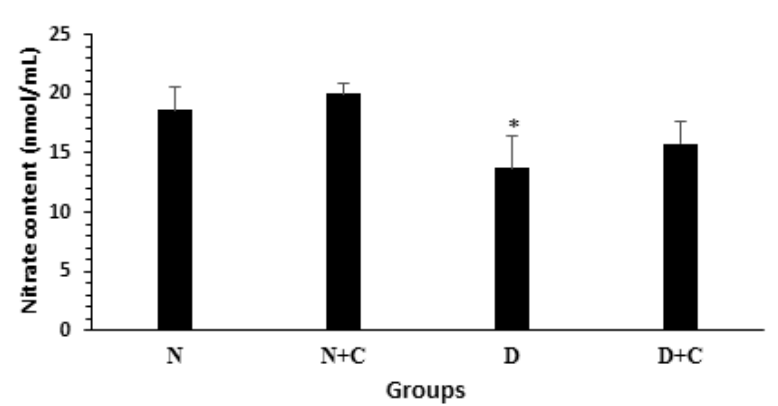

Figure 1 Representative changes of nitrate content $(\mathrm{nmol} / \mathrm{mL})$ in normal $(\mathrm{N})$, normal + crocin $(\mathrm{N}+\mathrm{C})$, diabetic $(\mathrm{D})$ and diabetic $+\operatorname{crocin}(\mathrm{D}+\mathrm{C})$ groups. All values are presented as Mean \pm SEM . * $(\mathrm{P}<0.001)$ significant differences relative to the control group (N)

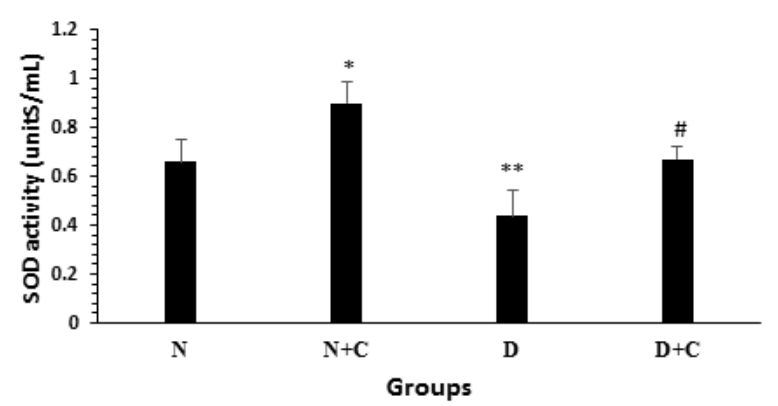

Figure 2 Representative changes of SOD activity (Units/mL) in normal $(\mathrm{N})$, normal + crocin $(\mathrm{N}+\mathrm{C})$, diabetic $(\mathrm{D})$ and diabetic + crocin $(D+C)$ groups. All values are presented as Mean \pm SEM. $*(\mathrm{P}<0.01)$ and ${ }^{* *}(\mathrm{P}<0.007)$ compared with the control group $(\mathrm{N})$ \# $(\mathrm{P}<0.003)$ compared with diabetic group (D)

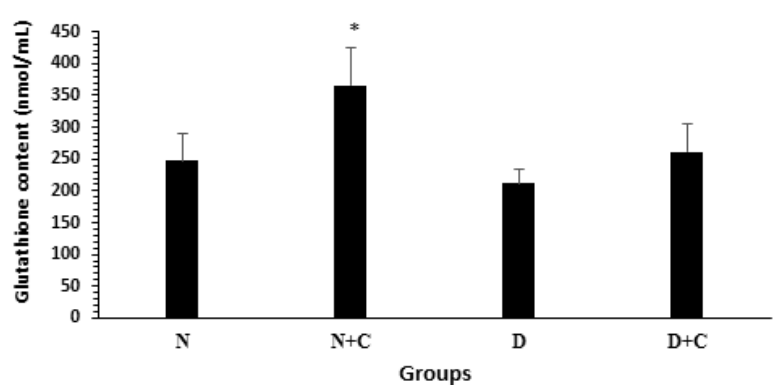

Figure 3 Representative changes of glutathione content (nmol/ $\mathrm{mL}$ ) in normal $(\mathrm{N})$, normal $+\operatorname{crocin}(\mathrm{N}+\mathrm{C})$, diabetic (D) and diabetic $+\operatorname{crocin}(D+C)$ groups. All values are presented as Mean \pm SEM.

$*(\mathrm{P}<0.00)$ compared with control group $(\mathrm{N})$

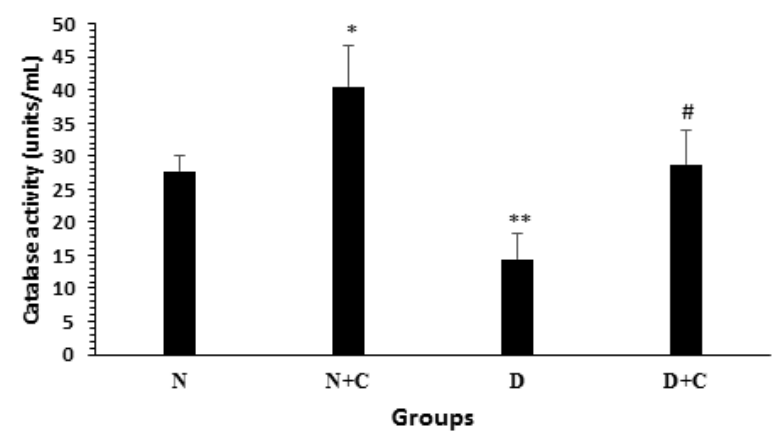

Figure 4 Representative changes of catalase activity (Units/mL) in normal $(\mathrm{N})$, normal $+\operatorname{crocin}(\mathrm{N}+\mathrm{C})$, diabetic (D) and diabetic $+\operatorname{crocin}(\mathrm{D}+\mathrm{C})$ groups. All values are presented as Mean \pm SEM. * $(\mathrm{P}<0.01)$ and ${ }^{* *}(\mathrm{P}<0.007)$ compared with control group $(\mathrm{N})$ \# $(\mathrm{P}<0.003)$ compared with diabetic group (D) 


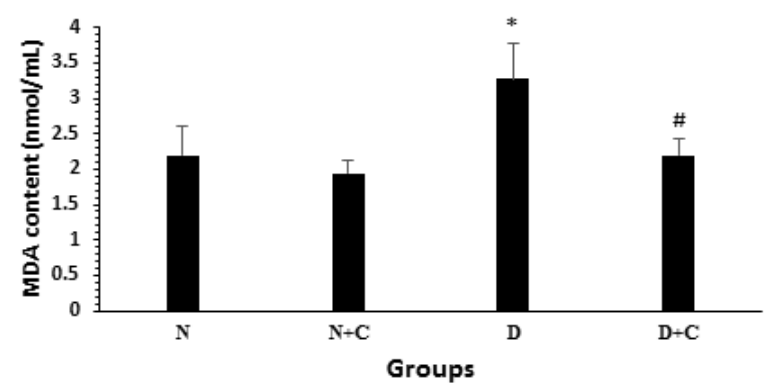

Figure 5 Representative changes of MDA content $(\mathrm{nmol} / \mathrm{mL})$ in normal $(\mathrm{N})$, normal + crocin $(\mathrm{N}+\mathrm{C})$, diabetic (D) and diabetic + crocin $(D+C)$ groups. All values are presented as Mean \pm SEM.

* $(\mathrm{P}<0.001)$ compared with control group $(\mathrm{N})$

\# $(\mathrm{P}<0.02)$ compared with diabetic group $(\mathrm{D})$

\subsection{Effects of diabetes and crocin on SOD enzyme activity}

Figure 2 shows representative changes of SOD enzyme activity in units $/ \mathrm{mL}$ in all groups. The mean value of the SOD activity in the normal group was $0.66 \pm 0.09$ units $/ \mathrm{mL}$. Crocin increased the SOD activity significantly to $0.9 \pm 0.09$ units/mL in normal-treated rats. Uncontrolled hyperglycemia decreased the activity of SOD to $0.43 \pm 0.11$ units/ $\mathrm{mL}(\mathrm{P}<0.007)$. Also, treatment with crocin in diabetic animals significantly $(\mathrm{P}<0.02)$ increased the activity of SOD to $0.67 \pm 0.05 \mathrm{nmol} / \mathrm{mL}$.

\subsection{Effects of diabetes and crocin on GLT content}

Figure 3 shows representative changes of GLT content in $\mathrm{nmol} / \mathrm{mL}$ in all groups. The mean value of GLT content in the normal group was $247 \pm 42 \mathrm{nmol} / \mathrm{mL}$. Crocin significantly $(\mathrm{P}<0.001)$ increased the GLT content to $366 \pm 60$ $\mathrm{nmol} / \mathrm{mL}$ in normal-treated rats. Uncontrolled hyperglycemia did not change the GLT content in non-treated rats. Also, treatment with crocin in diabetic animals did not change the GLT content.

\subsection{Effects of diabetes and crocin on the activity of catalase}

Figure 4 shows representative changes of catalase enzyme activity in units/mL in all groups. The mean value of catalase activity in the normal group was $27.77 \pm 2.44$ units/ $\mathrm{mL}$. Crocin significantly $(\mathrm{P}<0.01)$ increased catalase activity to $40.51 \pm 6.3$ units $/ \mathrm{mL}$ in normal-treated rats. Uncontrolled hyperglycemia decreased the activity of catalase to $14.47 \pm 3.78$ units $/ \mathrm{mL}(\mathrm{P}<0.007)$. Also, treatment with crocin in diabetic animals significantly $(\mathrm{P}<0.003)$ elevated the enzymatic activity of catalase to $28.77 \pm 5.18$ units $/ \mathrm{mL}$.

\subsection{Effects of diabetes and crocin on MDA content}

Figure 5 shows representative values of MDA content in $\mathrm{nmol} / \mathrm{mL}$ in all groups. The mean value of MDA content in the normal group was $2.19 \pm 0.40 \mathrm{nmol} / \mathrm{mL}$. Crocin did not change the levels of MDA in normal-treated rats. Uncontrolled hyperglycemia significantly $(\mathrm{P}<0.001)$ increased the MDA levels to $3.27 \pm 0.49 \mathrm{nmol} / \mathrm{mL}$. Treatment of diabetic animals with crocin significantly $(\mathrm{P}<0.02)$ lowered the levels of MDA to $2.62 \pm 0.26 \mathrm{nmol} / \mathrm{mL}(\mathrm{P}<0.02)$.

\section{Discussion}

In the current study, we showed that uncontrolled hyperglycemia can decrease SOD and catalase enzyme activity and, therefore, weaken the intrinsic antioxidant defense system leading to the development of OS in pancreatic cells. Next, our results demonstrated that treatment by crocin potentiates the anti-oxidant defense system and improved (reduced) OS in this tissue. Oxidative stress is a common process in uncontrolled hyperglycemia [2]. In this process, over-production of free radicals occurs and results in deleterious damage to a variety of biological molecules [1]. As a result, tissue function is disturbed and/or completely lost in susceptible tissues [3]. Thus, potentiation of the anti-oxidant defense system by pharmacological agents is an attractive field in many physiological-based investigations. Crocin, as a plant-derived agent and a hydrophilic natural beta-carotene, which is obtained from saffron, has many known biological effects. Past studies have shown that it exerts a potent antioxidant effect in various tissues [21]. However, to the best of our knowledge, there is currently no evidence concerning its effects in the pancreatic tissue, especially during diabetes. There are several seminal studies that have unequivocally demonstrated that diabetes can weaken the intrinsic anti-oxidant defense system in many tissues [36]. In this study, diabetes weakened the anti-oxidant defense system by significantly reducing the enzymatic activity of SOD and catalase in pancreatic cells. Fischer et al. suggested that alloxan-induced diabetes deteriorates anti-oxidative enzyme activity in rats [37]. Also, Marchetti et al. showed that pancreatic islet cells from diabetic subjects have functional defects that result from a reduction in anti-oxidant enzyme activity, which subsequently leads to OS [38]. These results were confirmed in our study. Oxidative stress has a pivotal role in pancreatic islet cell dysfunction $[3,6]$. With lowered circulating levels of insulin, lipotoxicity and apoptosis become the main consequences of hyperglycemia-mediated OS in pancreatic islet cells $[3,39,40]$. Chronic exposure of pancreatic tissue to free radicals can lead to a reduction in the expression of the insulin gene and further reduction of insulin secretion [3]. Thus, in a vicious cycle, OS can cause a further reduction of circulating insulin levels which, in turn, leads to increased free radical production and exacerbation of OS [3]. Excessive amounts of glucose and free radicals in the pancreas can also decrease PDX-1 and MafA transcription factors which, in turn, reduce insulin production [3]. Federici et al. demonstrated that isolated pancreatic islet cells cultured in a high-glucose environment showed increased apoptosis due to over-expression of Bad, Bik, and Bid pro-apoptotic factors [8]. 
The main components of the intrinsic anti-oxidative system in pancreatic cells are SOD, catalase and glutathione peroxidase [3]. Pancreatic cells, relative to other tissues, have a less potent anti-oxidative system [3]. Thus, it seems that this organ needs more support by anti-oxidative agents during a hyperglycemic state. Previous studies have shown the beneficial effects of crocin in a hyperglycemic environment in other tissues [20, 27]. Our results would seem to suggest that crocin potentiated the antioxidant defense system by increasing the enzymatic activities of SOD and catalase in the pancreas. As a result of increased activity of both SOD and catalase by crocin, MDA (as the main indicator of OS) production was decreased, which strongly supports our hypothesis that crocin decreased OS in the pancreas. It may be that crocin enhances the activity of these enzymes by directly increasing their gene expression. Beshbishi et al. demonstrated that crocin can directly enhance the mRNA expression of SOD and catalase [27]. Therefore, there is a need to conduct additional studies to reconfirm the antioxidant activity of crocin.

In our study, crocin had no significant effect on GLT content in diabetic rats but increased it in rats contained in the normal-treated group. Therefore, it seems that crocin has no effect on GLT content in a diabetic environment, though additional studies are needed to confirm or disprove this finding.

\section{Conclusion}

Our results demonstrated that uncontrolled diabetes can weaken the intrinsic anti-oxidative defense system and promote the development of OS in pancreatic cells. Also, we would suggest that crocin can reduce hyperglycemia-mediated OS by potentiating the intrinsic anti-oxidant defense system in pancreatic cells.

\section{Conflict of interests}

The authors have declared that there are no conflicts of interest in this study. Also, the authors declare that there was no financial support for this study.

\section{References}

1. Rains JL, Jain SK. Oxidative stress, insulin signaling, and diabetes. Free Radical Biology and Medicine. 2011;50(5):567-575.

2. Kashihara N, et al. Oxidative stress in diabetic nephropathy. Current medicinal chemistry. 2010;17(34):4256.

3. Robertson RP. Chronic oxidative stress as a central mechanism for glucose toxicity in pancreatic islet beta cells in diabetes. Journal of Biological Chemistry. 2004;279(41):42351-42354.

4. Baynes JW, Thorpe SR. Role of oxidative stress in diabetic complications: a new perspective on an old paradigm. Diabetes. 1999;48(1):1-9.

5. Maritim A, Sanders R, Watkins RJ. Diabetes, oxidative stress, and antioxidants: a review. J Biochem Mol Toxicol. 2003;17(2438.26).

6. Ihara Y, et al. Hyperglycemia causes oxidative stress in pancreatic beta-cells of GK rats, a model of type 2 diabetes. Diabetes. 1999;48(4):927.

7. Kakkar R, et al. Increased oxidative stress in rat liver and pancreas during progression of streptozotocin-induced diabetes. Clinical Science. 1998;94(6):623-632.

8. Federici M, et al. High Glucose Causes Apoptosis in Cultured Human Pancreatic Islets of Langerhans A Potential Role for Regulation of Specific Bcl Family Genes Toward an Apoptotic Cell Death Program. Diabetes. 2001;50(6):1290-1301.

9. Robertson RP, et al. Preservation of insulin mRNA levels and insulin secretion in HIT cells by avoidance of chronic exposure to high glucose concentrations. Journal of Clinical Investigation. 1992;90(2):320.

10. Harmon JS, et al. In vivo prevention of hyperglycemia also prevents glucotoxic effects on PDX-1 and insulin gene expression. Diabetes. 1999;48(10):1995-2000.

11. Lu M, Seufert J, Habener JF. Pancreatic $\beta$-cell-specific repression of insulin gene transcription by CCAAT/Enhancer-binding protein $\beta$ Inhibitory interactions with basic helix-loop-helix transcription factor E47. Journal of Biological Chemistry. 1997;272(45):28349-28359.

12. Seufert J, Weir GC, Habener JF. Differential expression of the insulin gene transcriptional repressor CCAAT/ enhancer-binding protein beta and transactivator islet duodenum homeobox-1 in rat pancreatic beta cells during the development of diabetes mellitus. Journal of Clinical Investigation. 1998;101(11):2528.

13. Briaud I, et al. Lipotoxicity of the pancreatic $\beta$-cell is associated with glucose-dependent esterification of fatty acids into neutral lipids. Diabetes. 2001;50(2):315-321.

14. Sobhani Z, et al. Medicinal plants targeting cardiovascular diseases in view of avicenna. Current Pharmaceutical Design. 2017;23(17):2428-2443.

15. Shafiee M, et al. Saffron in the treatment of depression, anxiety and other mental disorders: Current evidence and potential mechanisms of action. Journal of Affective Disorders. 2017;227:330-337.

16. Riazi A, et al. The impact of saffron (Crocus sativus) supplementation on visual function in patients with dry age-related macular degeneration. Italian Journal of Medicine. 2017;11(2):196-201.

17. Javadi B, Sahebkar A, Emami SA. Medicinal plants for the treatment of asthma: A traditional persian medicine perspective. Current Pharmaceutical Design. 2017;23(11)1623-1632.

18. Javadi B, Sahebkar A, Emami SA. A survey on saffron in major Islamic traditional medicine books. Iranian Journal of Basic Medical Sciences. 2013;16(1):1-11.

19. Emami SA, Sahebkar A, Javadi B. Paresthesia: A review of its definition, etiology and treatments in view of the traditional medicine. Current Pharmaceutical Design. 2016;22(3):321-327.

20. Ochiai T, et al. Crocin prevents the death of rat pheochromyctoma (PC-12) cells by its antioxidant effects stronger than those of $\alpha$-tocopherol. Neuroscience letters. 2004;362(1):61-64.

21. Chen Y, et al. Antioxidant potential of crocins and ethanol extracts of Gardenia jasminoides ELLIS and Crocus sativus L.: A relationship investigation between antioxidant activity and crocin contents. Food Chemistry. 
2008;109(3):484-492.

22. Nikbakht-Jam I, et al. Effect of crocin extracted from saffron on pro-oxidant-anti-oxidant balance in subjects with metabolic syndrome: A randomized, placebo-controlled clinical trial. European Journal of Integrative Medicine. 2015;8(3):307-312.

23. Rahiman N, et al. Protective effects of saffron and its active components against oxidative stress and apoptosis in endothelial cells. Microvascular Research. 2018;118:82-89.

24. Jam IN, et al. The effects of crocin on the symptoms of depression in subjects with metabolic syndrome. Advances in Clinical and Experimental Medicine. 2017;26(6):925-930.

25. Hosseini A, Sahebkar A. Reversal of doxorubicin-induced cardiotoxicity by using phytotherapy: A review. Journal of Pharmacopuncture. 2017;20(4):243-256.

26. Krinsky NI. Antioxidant functions of carotenoids. Free Radical Biology and Medicine. 1989;7(6):617-635.

27. El-Beshbishy HA, et al. Crocin "saffron" protects against beryllium chloride toxicity in rats through diminution of oxidative stress and enhancing gene expression of antioxidant enzymes. Ecotoxicology and environmental safety. 2012;83:47-54.

28. Yaribeygi H, Mohammadi MT, Sahebkar A. Crocin potentiates antioxidant defense system and improves oxidative damage in liver tissue in diabetic rats. Biomedicine and Pharmacotherapy. 2018;98:333-337.

29. Hemshekhar M, et al. A dietary colorant crocin mitigates arthritis and associated secondary complications by modulating cartilage deteriorating enzymes, inflammatory mediators and antioxidant status. Biochimie. 2012;94(12):2723-2733.

30. Jnaneshwari S, et al. Crocin, a dietary colorant mitigates cyclophosphamide-induced organ toxicity by modulating antioxidant status and inflammatory cytokines. Journal of Pharmacy and Pharmacology. 2013;65(4):604-614.

31. Yaribeygi $\mathrm{H}$, et al. Crocin improves renal function by declining Nox-4, IL-18, and p53 expression levels in an experimental model of diabetic nephropathy. Journal of Cellular Biochemistry. 2018;119(7):6080-6093.

32. Winterbourn CC, et al. The estimation of red cell superoxide dismutase activity. The Journal of laboratory and clinical medicine. 1975;85(2):337-341.

33. Aebi H. [13] Catalase in vitro. Methods in enzymology. 1984;105(C):121-126.

34. Tietze F. Enzymic method for quantitative determination of nanogram amounts of total and oxidized glutathione: applications to mammalian blood and other tissues. Analytical biochemistry. 1969;27(3):502-522.

35. Satoh M, et al. NAD (P) H oxidase and uncoupled nitric oxide synthase are major sources of glomerular superoxide in rats with experimental diabetic nephropathy. American Journal of Physiology-Renal Physiology. 2005;288(6):F1144-F1152.

36. El-Missiry MA. Enhanced testicular antioxidant system by ascorbic acid in alloxan diabetic rats. Comparative Biochemistry and Physiology Part C: Pharmacology, Toxicology and Endocrinology. 1999;124(3):233-237.

37. Fischer L, Hamburger S. Inhibition of alloxan action in isolated pancreatic islets by superoxide dismutase, catalase, and a metal chelator. Diabetes. 1980;29(3):213216.

38. Marchetti P, et al. Pancreatic islets from type 2 diabetic patients have functional defects and increased apoptosis that are ameliorated by metformin. The Journal of Clinical Endocrinology \& Metabolism. 2004;89(11):5535-5541.

39. LeRoith D, Taylor SI, Olefsky JM. Diabetes mellitus: a fundamental and clinical text. Lippincott Williams \& Wilkins; 2004.

40. Kaneto $\mathrm{H}$, et al. Involvement of c-Jun $\mathrm{N}$-terminal kinase in oxidative stress-mediated suppression of insulin gene expression. Journal of Biological Chemistry. 2002;277(33):30010-30018. 